\title{
PENINGKATAN PERSEPSI KARYAWAN TERHADAP OBJEKTIVITAS PENILAIAN KINERJA MENGGUNAKAN METODE BARS DAN MBO
}

\author{
Wulan Purnamasari ${ }^{1}$, Ika Widya Ardhiyani ${ }^{2}$ \\ Program Studi Manajemen, Universitas Maarif Hasyim Latif ${ }^{1}$ \\ Program Studi Teknik Industri, Universitas Maarif Hasyim Latif ${ }^{2}$ \\ e-mail:wulan_purnamasari@dosen.umaha.ac.id¹,ika.widya.ardhyani@gmail.com²
}

\begin{abstract}
The performance appraisal system in a company has an important role in achieving the target of achieving a job. Employee job satisfaction with the performance appraisal system depends on the level of employee perceptions of the performance appraisal system that applies to their workplace. This research was conducted in a company PT X which is engaged in the BOPP film industry. The performance appraisal system in the company, based on employee perceptions, is still not effective. Here, the researcher attempted to design a performance appraisal system using the BARS and MBO methods. This research was conducted by means of field surveys, literature studies, and FGDs. The BARS and MBO methods are able to assess employee performance. Where in this method it creates unclear and measurable performance standards, there is no maximum feedback on the performance of employees, often the assessment is subjective, besides the assessment is carried out once a year so that it causes management to experience difficulties in monitoring. In addition, the company only dominantly assesses work activities and behavior, without assessing the work performance of each employee. Whereas here, the company should have carried out an objective performance appraisal, by having clear and measurable assessment standards and being able to provide feedback on employee performance achievements. Thus, researchers recommend using the BARS and $M B O$ methods in the performance appraisal process. This aims to meet the company's needs for employee performance appraisals.
\end{abstract}

Keywords: employee perceptions, objectivity of performance appraisal, BARS, MBO

\section{PENDAHULUAN}

Sumber daya manusia memiliki peran penting dalam berjalannya roda perusahaan di era Industri 4.0, di mana kompetisi antar-perusahaan semakin ketat. Pasar menuntut perusahaan agar dapat menyediakan pelayanan terbaik kepada customer dan mitra bisnisnya. Kondisi ini mendorong sumber daya manusia untuk mampu memberikan performa terbaik, dengan keadaan ini maka perusahaan harus mampu berkompetisi secara sehat dan sportif dengan para kompetitornya. Salah satu aktivitas dalam manajemen sumber daya manusia ialah penilaian kinerja karyawan. Pihak manajemen perusahaan memiliki ekspektasi tinggi terhadap kinerja karyawannya.
Dengan demikian, untuk mengetahui apakah harapan perusahaan terhadap kinerja karyawannya sudah tercapai atau belum dan telah memenuhi standar kriteria perusahaan atau belum. Oleh karena itu, diperlukan penilaian kinerja dengan menggunakan metode yang tepat dan efektif. PT X adalah perusahaan Industry Biaxially Oriented Polypropylene (BOPP) Film dan Polyester Film.

Permasalahan pada penelitian ini adalah PT $\mathrm{X}$ melakukan penilaian kinerja dengan menggunakan metode rating scale dan check list. $\mathrm{Na}$ mun, dari hasil penilaian masih dirasakan belum efektif sesuai dengan ekspektasi manajemen. Hal ini disebabkan karena adanya kelemahan, yaitu persepsi karyawan terhadap objektivitas 
penilaian kinerja bersifat negatif, penilaian yang dianggap subjektif oleh karyawan, tidak ada standar atau kriteria yang terukur dan jelas, terjadi hello effect, dan lebih memprioritaskan kriteria pribadi karyawan dibandingkan dengan kriteria hasil kerja. Oleh karena itu, banyak karyawan yang merasa tidak adil dengan hasil penilaian kinerja yang diberikan serta mereka juga tidak nyaman dan merasa tidak termotivasi dalam bekerja. Urgensi penelitian ini yaitu dengan adanya perancangan sistem penilaian kinerja pada kedua model ini dapat mengatasi masalah yang dihadapi oleh PT X, agar karyawan dapat merasakan keadilan dalam penilaian kinerja, merasa nyaman, dan lebih termotivasi bekerja lebih baik. Tentunya hal ini nanti juga akan menguntungkan bagi pihak manajemen perusahaan dalam meraih target capaian keberhasilan perusahaan.

\section{METODE}

\section{Subjek Penelitian}

Subjek pada penelitian ini adalah karyawan PT X bagian produksi pada tiha jabatan yaitu operator, foreman, dan SPV. Untuk masingmasing jabatan diambil sampel sebanyak 10 subjek, dengan demikian total subjek penelitian adalah 30. Pengambilan sampel penelitian menggunakan purposive sampling, dengan ketentuan subjek adalah karyawan tetap minimal telah bekerja di bidangnya minimal dua tahun.

\section{Pengamatan Awal}

Tahapan pertama, tim peneliti (ketua dan anggota) melakukan pengamatan dengan cara mengidentifikasi dari perumusan masalah yang ada di perusahaan PT X.

\section{Studi Literatur}

Peneliti mengumpulkan serta memahami teori-teori dari berbagai referensi dan hasil penelitian terdahulu yang berhubungan dengan permasalahan dalam penelitian ini, yaitu mengenai performance appraisal dengan menggunakan metode BARS dan MBO.

\section{Pengumpulan Data}

\section{Sumber Data}

Tim peneliti menggali informasi berasal dari sumber data berupa data primer dan sekunder. Data primer yaitu data yang didapatkan dari hasil wawancara dan kuesioner terhadap kinerja karyawan. Data primer yang digunakan meliputi atribut serta kriteria kinerja karyawan.

Sedangkan data sekunder pada penelitian ini yaitu data kepustakaan yang didapatkan dari berbagai referensi dan hasil penelitian terdahulu.

\section{Teknik Pengumpulan Data}

Teknik pengumpulan data pada penelitian ini data meliputi hal-hal sebagai berikut.

1. Field research

Tim peneliti mengamati pekerjaan karyawan dan segala prosedur yang telah diterapkan perusahaan.

2. Studi pustaka

Tim peneliti mempelajari berbagai buku literatur, karya ilmiah, jurnal, dan penelitian terdahulu mengenai performance appraisal serta mengumpulkan data serta berbagai informasi perusahaan yang meliputi struktur organisasi, data perusahaan, data karyawan, job description karyawan, dan performance appraisal karyawan. 


\section{Melakukan wawancara}

Anggota peneliti melakukan sesi tanya jawab secara langsung pada pihak perusahaan yang dianggap benar-benar memahami masalah dalam penelitian. Bentuk pertanyaan tidak dipusatkan pada pokok persoalan tentang penilaian kinerja karyawan saja, namun memberikan pertanyaan dalam lingkup yang luas. Tim peneliti mempersiapkan kerangka pertanyaan yang kemudian dikembangkan disesuaikan dengan kondisi di lapangan.

4. FGD (focus group discussion)

Untuk menentukan kriteria penilaian dalam aplikasi metode $\mathrm{MBO}$ serta mengurutkan anchor dari setiap dimensi performance appraisal dengan menggunakan metode BARS, peneliti harus merumuskannya bersama manajer masing-masing departemen dan perwakilan karyawan dari departemen.

\section{Analisis Data}

Perumusan performance appraisal dengan BARS. Tim peneliti menentukan dimensi dan indikator dari sikap kinerja karyawan, yang kemudian ditentukan pula skala pemeringkatannya (rating scale) dengan menggunakan skala Likert jenjang 5 .

\section{Perumusan Performance Appraisal dengan MBO}

Tim peneliti membuat perumusan performance appraisal dengan menggunakan metode $\mathrm{MBO}$, dimulai dengan mengumpulkan data mulai tujuan PT X hingga tujuan spesifik yang harus dicapai dan dilaksanakan oleh karyawan. Dalam hal ini dibutuhkan deep interview agar mendapatkan jawaban yang valid.

\section{Analisis Tujuan Perusahaan}

Ketua peneliti menganalisis tujuan spesifik perusahaan PT X, baik tujuan jangka pendek, tujuan jangka menengah, maupun jangka panjang.

\section{Analisis Tujuan Departemen}

Tim peneliti menganalisis tujuan departemen. Analisis ini berfungsi untuk mengetahui tujuan spesifik dari masing-masing departemen yang nantinya akan dijadikan sebagai tolok ukur dalam pelaksanaan kinerja karyawan dan perlu adanya pengelompokan tujuan berdasarkan fungsi departemen itu sendiri.

\section{Perumusan Bobot dan Target Capaian Setiap Karyawan}

Tim peneliti menyusun perumusan bobot dan target capaian setiap karyawan dilakukan dengan cara menurunkannya dari tujuan PT X beserta tujuan dari tiap departemen.

Tim peneliti mengadakan diskusi bersama manager dan perwakilan dari tiap departemen serta menganalisis job description karyawan, proses ini memiliki tujuan untuk mendapatkan indicator apa saja yang harus dicapai oleh karyawan PT X.

\section{HASIL DAN PEMBAHASAN}

Perumusan Penilaian dengan metode behaviorally anchor rating scale (BARS)

Berdasarkan hasil analisis gap yang telah dilakukan sebelumnya, maka BARS untuk menilai dimensi perilaku kerja karyawan dan $\mathrm{MBO}$ untuk menilai hasil kerja karyawan dapat dilihat pada Tabel 1. 
Tabel 1 Perumusan Penilaian dengan Metode Behaviorally Anchor Rating Scale (BARS)

\begin{tabular}{|c|c|c|c|}
\hline No. & Indicator & Scale & Anchor \\
\hline \multicolumn{4}{|c|}{ Operator Departemen Produksi } \\
\hline \multirow[t]{5}{*}{1} & \multirow{5}{*}{$\begin{array}{l}\text { Kemampuan dalam } \\
\text { mengoperasikan mesin/ } \\
\text { alat yang menjadi } \\
\text { tanggung jawabnya }\end{array}$} & 5 & $\begin{array}{l}\text { Mampu mengoperasikan mesin sesuai SOP, mengetahui gejala } \\
\text { yang timbul apabila mesin akan mengalami trouble, mampu } \\
\text { merawat (maintenance) dan mengedepankan K3 }\end{array}$ \\
\hline & & 4 & $\begin{array}{l}\text { Mampu mengoperasikan mesin sesuai SOP dan mengetahui } \\
\text { gejala yang timbul apabila mesin akan mengalami trouble }\end{array}$ \\
\hline & & 3 & Mampu mengoperasikan mesin sesuai SOP \\
\hline & & 2 & Dapat mematikan, menghidupkan serta mengoperasikan mesin \\
\hline & & 1 & Hanya mampu menghidupkan dan mematikan mesin saja \\
\hline \multirow[t]{5}{*}{2} & \multirow{5}{*}{$\begin{array}{l}\text { Bekerja sesuai SOP } \\
\text { (standard operational } \\
\text { procedure) }\end{array}$} & 5 & $\begin{array}{l}\text { Bekerja dengan mematuhi SOP, memperhatikan keselamatan diri } \\
\text { dan orang-orang di sekitar lingkungan kerja }\end{array}$ \\
\hline & & 4 & Bekerja dengan mematuhi SOP, memperhatikan keselamatan diri \\
\hline & & 3 & $\begin{array}{l}\text { Bekerja dengan mematuhi SOP dan mendengarkan instruksi } \\
\text { atasan }\end{array}$ \\
\hline & & 2 & $\begin{array}{l}\text { Bekerja dengan mematuhi SOP namun masih sering dengan cara } \\
\text { sendiri }\end{array}$ \\
\hline & & 1 & Bekerja dengan tidak mematuhi SOP \\
\hline \multirow[t]{5}{*}{3} & \multirow[t]{5}{*}{ Bekerja sesuai target } & 5 & Menyusun target pencapaian yang realistis dan matang \\
\hline & & 4 & Meningkatkan performa kerja \\
\hline & & 3 & Berusaha mencapai target dengan memenuhi standar perusahaan \\
\hline & & 2 & Berusaha bekerja dengan baik \\
\hline & & 1 & Hanya focus bekerja, tanpa memikirkan target yang dicapai \\
\hline \multirow[t]{5}{*}{4} & \multirow[t]{5}{*}{$\begin{array}{l}\text { Kemampuan membuat } \\
\text { laporan }\end{array}$} & 5 & $\begin{array}{l}\text { Membuat laporan berdasarkan kenyataan di lapangan, mampu } \\
\text { menyebutkan kendala yang terjadi dan mampu memberikan } \\
\text { masukan/ solusi }\end{array}$ \\
\hline & & 4 & $\begin{array}{l}\text { Membuat laporan berdasarkan kenyataan di lapangan, mampu } \\
\text { menyebutkan kendala yang terjadi }\end{array}$ \\
\hline & & 3 & Membuat laporan berdasarkan kenyataan di lapangan \\
\hline & & 2 & Membuat laporan singkat dan seadanya \\
\hline & & 1 & Tidak membuat laporan \\
\hline \multirow[t]{5}{*}{5} & \multirow{5}{*}{$\begin{array}{l}\text { Menjaga dan } \\
\text { memelihara lingkungan } \\
\text { kerja }\end{array}$} & 5 & $\begin{array}{l}\text { Menjaga dan memelihara lingkungan kerja di departemen sendiri } \\
\text { dan departemen lain serta lingkungan eksternal perusahaan }\end{array}$ \\
\hline & & 4 & $\begin{array}{l}\text { Menjaga dan memelihara lingkungan kerja di departemen sendiri } \\
\text { dan departemen lain }\end{array}$ \\
\hline & & 3 & Menjaga dan memelihara lingkungan kerja di departemen sendiri \\
\hline & & 2 & Hanya menjaga keamanan lingkungan kerja saja \\
\hline & & 1 & Tidak menjaga dan memelihara lingkungan kerja \\
\hline \multicolumn{4}{|c|}{ Foreman Departemen Produksi } \\
\hline & $\begin{array}{l}\text { Kemampuan dalam me- } \\
\text { ngontrol pekerjaan yang } \\
\text { dikerjakan oleh } \\
\text { operator }\end{array}$ & 5 & $\begin{array}{l}\text { Mengontrol pekerjaan operator setiap waktu, inisiatif membantu } \\
\text { operator apabila mengalami kesulitan dan memotivasi kembali } \\
\text { agar operator tetap semangat bekerja }\end{array}$ \\
\hline & & 4 & $\begin{array}{l}\text { Mengontrol pekerjaan operator setiap waktu dan membantu } \\
\text { operator apabila mengalami kesulitan dalam menjalankan } \\
\text { pekerjaannya }\end{array}$ \\
\hline & & 3 & Mengontrol pekerjaan operator setiap waktu \\
\hline & & 2 & Mengontrol pekerjaan operator akhir bulan saja \\
\hline & & 1 & Tidak pernah mengontrol pekerjaan operator sama sekali \\
\hline & $\begin{array}{l}\text { Kemampuan memotori- } \\
\text { sasi pekerjaan yang } \\
\text { dilakukan operator }\end{array}$ & 5 & $\begin{array}{l}\text { Memotorisasi pekerjaan operator dengan pengawasan dan sesuai } \\
\text { SOP serta memberikan evaluasi }\end{array}$ \\
\hline
\end{tabular}


Wulan Purnamasari, Ika Widya Ardhiyani, Peningkatan Persepsi Karyawan terhadap Objektivitas Penilaian Kinerja Menggunakan Metode BARS dan MBO

\begin{tabular}{|c|c|c|c|}
\hline & & 4 & $\begin{array}{l}\text { Mengontrol pekerjaan operator setiap waktu dan membantu } \\
\text { operator apabila mengalami kesulitan dalam menjalankan } \\
\text { pekerjaannya }\end{array}$ \\
\hline & & 3 & Mengontrol pekerjaan operator setiap waktu \\
\hline & & 2 & Mengontrol pekerjaan operator akhir bulan saja \\
\hline & & 1 & Tidak pernah mengontrol pekerjaan operator sama sekali \\
\hline & $\begin{array}{l}\text { Kemampuan memotori- } \\
\text { sasi pekerjaan yang } \\
\text { dilakukan operator }\end{array}$ & 5 & $\begin{array}{l}\text { Memotorisasi pekerjaan operator dengan pengawasan dan sesuai } \\
\text { SOP serta memberikan evaluasi }\end{array}$ \\
\hline & & 4 & $\begin{array}{l}\text { Memotorisasi pekerjaan operator dengan pengawasan dan sesuai } \\
\text { SOP }\end{array}$ \\
\hline & & 3 & Memotorisasi pekerjaan operator dengan pengawasan \\
\hline & & 2 & Memotorisasi pekerjaan operator tanpa pengawasan \\
\hline & & 1 & $\begin{array}{l}\text { Tidak pernah sama sekali memberikan contoh dalam teknis } \\
\text { pekerjaan kepada operator }\end{array}$ \\
\hline & $\begin{array}{l}\text { Kemampuan menjaga } \\
\text { stabilitas pekerjaan agar } \\
\text { aman }\end{array}$ & 5 & $\begin{array}{l}\text { Bekerja menjaga keamanan stabilitas pekerjaan untuk diri } \\
\text { sendiri, operator dan semua yang terlibat dalam lingkungan } \\
\text { perusahaan }\end{array}$ \\
\hline & & 4 & $\begin{array}{l}\text { Bekerja menjaga keamanan stabilitas pekerjaan untuk diri sendiri } \\
\text { dan operator }\end{array}$ \\
\hline & & 3 & Bekerja menjaga keamanan stabilitas pekerjaan untuk diri sendiri \\
\hline & & 2 & Hanya focus bekerja \\
\hline & & 1 & Melalaikan stabilitas keamanan kerja \\
\hline & $\begin{array}{l}\text { Kemampuan menjadi } \\
\text { problem solver terhadap } \\
\text { permasalahan di } \\
\text { lapangan }\end{array}$ & 5 & $\begin{array}{l}\text { Mampu merumuskan alternatif solusi yang relevan untuk } \\
\text { menyelesaikan masalah }\end{array}$ \\
\hline & & 4 & Menciptakan solusi temporer atas masalah yang terjadi \\
\hline & & 3 & $\begin{array}{l}\text { Mampu membuat keputusan tanpa pertimbangan reaksi dari } \\
\text { operator }\end{array}$ \\
\hline & & 2 & $\begin{array}{l}\text { Mementingkan kepentingan pribadi pada saat membuat } \\
\text { keputusan }\end{array}$ \\
\hline & & 1 & Menolak membuat keputusan saat dibutuhkan \\
\hline & $\begin{array}{l}\text { Kemampuan menjadi } \\
\text { analisator terhadap } \\
\text { permasalahan yang } \\
\text { timbul di area pekerjaan }\end{array}$ & 5 & Mampu membuat analisis masalah dan mencari solusinya \\
\hline & & 4 & Mampu melihat hubungan dasar masalah \\
\hline & & 3 & Mampu melihat penyebab masalah \\
\hline & & 2 & Mampu memanfaatkan masalah \\
\hline & & 1 & Tidak mampu menguraikan masalah sama sekali \\
\hline \multicolumn{4}{|c|}{ Supervisor Departemen Produksi } \\
\hline & Kemampuan memimpin & 5 & Bertindak tegas dan tidak memihak, serta bisa menjadi teladan \\
\hline & & 4 & $\begin{array}{l}\text { Bertindak tegas dan tidak memihak serta mampu mengemukakan } \\
\text { pendapat dengan tegas }\end{array}$ \\
\hline & & 3 & Bersikap sedikit memihak, namun masih dalam batas wajar \\
\hline & & 2 & Mudah dipengaruhi \\
\hline & & 1 & Tidak mampu bertindak tegas dan cenderung memihak \\
\hline & Berpikir kritis & 5 & Membuat Analisis yang kompleks \\
\hline & & 4 & Melihat hubungan yang kompleks antar-masalah \\
\hline & & 3 & Mampu melihat hubungan dasar antar-masalah \\
\hline & & 2 & Mampu memanfaatkan masalah \\
\hline & & 1 & Tidak mampu menguraikan masalah \\
\hline
\end{tabular}




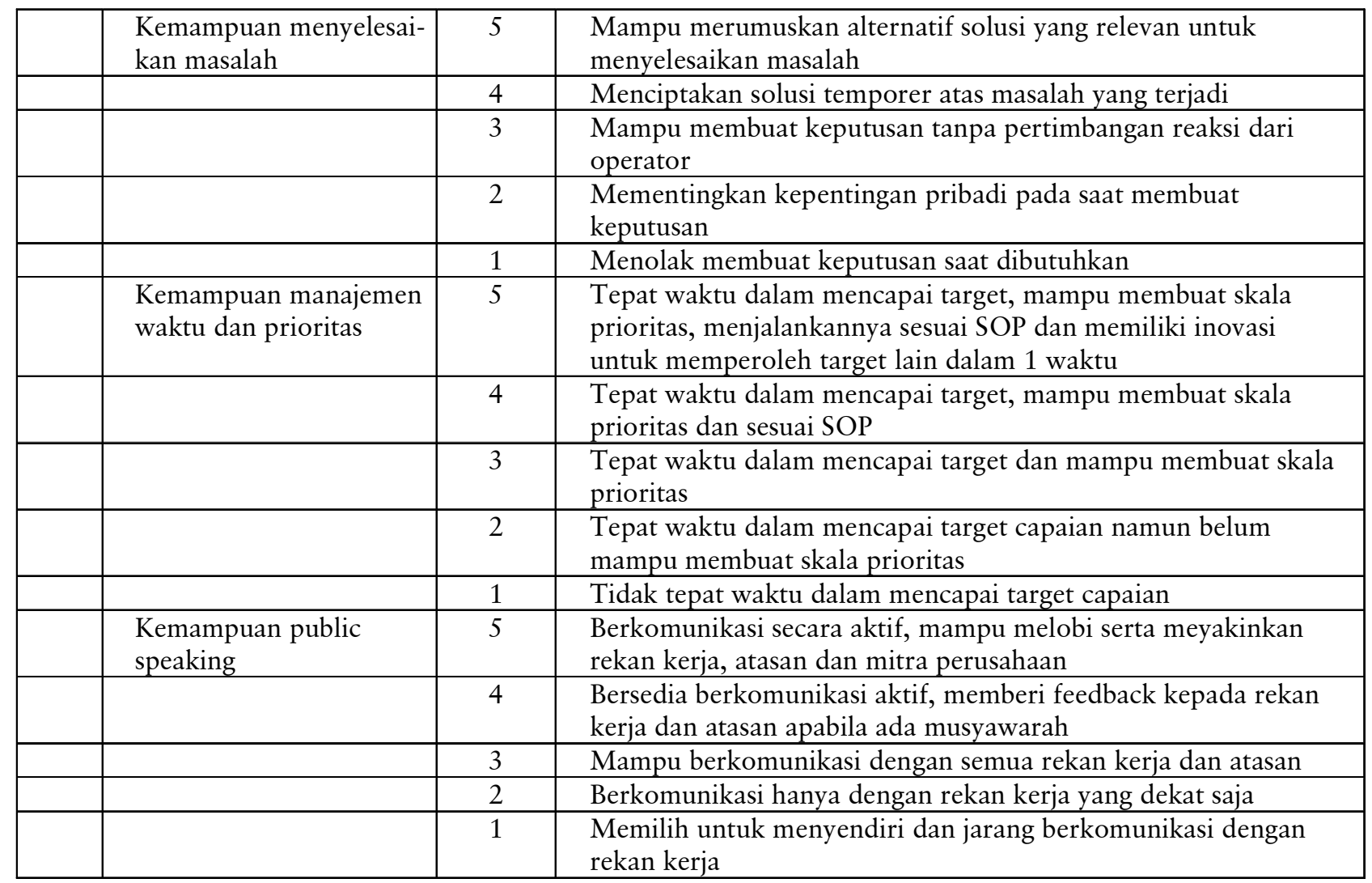

Sumber: Berdasarkan hasil survei di PT X

\section{Perumusan Penilaian Kinerja dengan Manage- ment by Objectives (MBO)}

Dalam proses penilaian kinerja karyawan dengan menggunakan metode $\mathrm{MBO}$ ini meliputi beberapa tahapan, di mana pimpinan diharapkan dapat mengomunikasikan kepada para karyawan. Dengan demikian dibutuhkan adanya pengawasan secara kontinu guna mengetahui sejauh mana capaian karyawan. Adapun tahapan meliputi beberapa hal sebagai berikut.

\section{Analisis tujuan perusahaan}

Berdasarkan hasil wawancara diperoleh tujuan PT X sebagai berikut.

a. Menjadi mitra bisnis yang inovatif, diminati, dan diakui secara global.

b. Meningkatkan keuntungan bagi pemegang saham. c. Membangun jaringan luas dengan para supply chain dan konsumen dalam jangka panjang.

2. Analisis tujuan departemen

Pada departemen produksi terdapat tujuan sebagai berikut.

a. Menghasilkan produk berkualitas dengan reject material kurang dari 5\%.

b. Menghasilkan produk dengan kuantitas yang tepat dan tepat waktu.

3. Perumusan bobot serta target tiap karyawan. Perumusan bobot dan target tiap karyawan dilakukan dengan menurunkan tujuan perusahaan dan tujuan departemen. Penentuan bobot dan target karyawan disusun melalui hasil diskusi dengan pimpinan dan para karyawan. 
Wulan Purnamasari, Ika Widya Ardhiyani, Peningkatan Persepsi Karyawan terhadap Objektivitas Penilaian Kinerja Menggunakan Metode BARS dan MBO

Tabel 2 Bobot dan Target Karyawan di Departemen Produksi PT X

\begin{tabular}{|c|l|c|c|}
\hline No. & \multicolumn{1}{|c|}{ Indikator } & Bobot & Target \\
\hline 1 & Ketepatan kuantitas produksi & 25 & $100 \%$ \\
\hline 2 & Ketepatan kualitas produksi & 25 & $100 \%$ \\
\hline 3 & Jumlah reject material kurang dari 5\% & 25 & $100 \%$ \\
\hline 4 & Jumlah mesin yang beroperasi & 25 & $>85 \%$ \\
\hline
\end{tabular}

\section{KESIMPULAN}

Penilaian kinerja karyawan yang telah diterapkan oleh PT X menggunakan laporan kerja harian karyawan dengan menggunakan metode skala rating. Di mana dalam metode tersebut menimbulkan standar kinerja yang tidak jelas dan terukur, belum ada feedback secara maksimal atas capaian kinerja karyawan, seringkali penilaian mengarah secara subjektif selain itu penilaian dilakukan satu tahun sekali sehingga mengakibatkan manajemen mengalami kesulitan dalam pengawasan. Selain itu perusahaan hanya dominan menilai aktivitas dan perilaku kerja saja, dengan tidak menilai hasil capaian kerja setiap karyawan. Padahal di sini seharusnya perusahaan harus melakukan penilaian kinerja secara objektif dengan memiliki standar penilaian yang jelas dan terukur serta mampu memberikan feedback atas capaian kinerja karyawan. Dengan demikian, peneliti merekomendasikan untuk menggunakan metode BARS dan MBO dalam proses penilaian kinerja. Hal ini bertujuan untuk memenuhi kebutuhan perusahaan terhadap penilaian kinerja karyawan.

\section{DAFTAR RUJUKAN}

Ayomikun O, Idowu. (2017). Effectiveness of Performance Appraisal System and Its Effect on Employee Motivation. Nile Journal of Business and Economics, 5, pp. 1539. London: Nile University of London.
Byars. L. el. (2014). Human Resource Management, 5th Edition. Chicago: McGrawHill Companies. Inc.

Dessler, G. 2013. Human Resource Management, 13th Edition. London: Pearson Prentice Hall Inc.

Evita, Siti dkk. 2017. Penilaian Kinerja Karyawan dengan Menggunakan Metode Behaviorally Anchor Rating Scale dan Management by Objectives (Studi Kasus pada PT Qwords Company International). Pekbis Jurnal, Vol. 9, No. 1. Bandung: Universitas Padjadjaran.

Hidayat, Rahmat. (2015). Performance Appraisal sebagai Alat Pengukuran Kepuasan Kerja Karyawan. Jurnal Ilman, Vol. 3, No. 1, pp. 1-8.

Islami, X., Mulolli, E., \& Mustafa, N. (2018). Using Management by Objectives as a Performance Appraisal Tool for Employee Satisfaction. Future Business Journal, 4(1), 94-108.

Khanna, Manish \& Rajneesh Kumar Sharma. (2014). Employees Performance Appraisal and Its Techniques: A Review. Asian Journal of Adv. Basic Sci: 2(2), pp. 51-58. Career Point University.

Kustiadi, O. \& Ikatrinasari, Z. F. (2018). Perancangan Penilaian Kinerja dengan Metode Behaviorally Anchor Rating Scale di PT ZENO Alumni Indonesia. Jurnal INKOFAR, 1(1). 
Permana, Ryan \& Zulfa Fitri. 2020. Designing of Performance Management System for Auditor Certification Body Using Management by Objective and Behaviorally Anchor Rating Scale. Proceedings on Engineering Sciences. Pes Journal, Vol. 02, No.2, pp. 179-186.

Suradija, Herman. (2015). Penyusunan Penilaian Kinerja Model BARS untuk Meningkatkan Persepsi Karyawan Terhadap Objektivitas
Penilaian Kinerja. Yogyakarta: Universitas Mercu Buana. Jurnal Sosio-Humaniora, Vol. 6, No. 1.

Taufik, dkk. (2014). Perancangan Aplikasi Sistem Penilaian Kinerja Karyawan dengan Metode MBO dan BARS (Studi Kasus PLTA Maninjau). Jurnal Optimasi Sistem Industri, Vol. 13, No. 2. Universitas Andalas. 